\title{
Syncope caused by congenital anomaly at the craniovertebral junction: a case report
}

\author{
Naohisa Miyakoshi", Michio Hongo, Yuji Kasukawa and Yoichi Shimada
}

\begin{abstract}
Introduction: Anomalies in the craniovertebral junction may be a rare cause of syncope. The mechanisms of syncope related to craniovertebral junction anomaly remain unknown.

We present an extremely rare case with anomaly in the craniovertebral junction and syncope, and discuss the mechanism of the syncope.

Case presentation: A 10-year-old Japanese boy with a congenital anomaly in the craniovertebral junction presented with recurrent syncope. A physical examination showed generalized hyperreflexia, but motor and sensory examinations were normal. Computed tomography and magnetic resonance imaging showed basilar invagination and spinal cord compression at his craniovertebral junction. Three-dimensional computed tomography angiography revealed an anomalous course of his bilateral vertebral arteries, both of which showed a persistent first intersegmental artery that entered the spinal canal at the caudal portion of the $\mathrm{C} 1$ posterior arch. In this case, the arteries were nearly pinched between the $\mathrm{C} 1$ posterior arch and the pars interarticularis of the C2. C1 laminectomy and occiput-cervical fusion (O-C2) was performed using an instrumentation system. After surgery, the syncope was not observed.

Conclusions: Syncope can be related to compression of extracranial arteries within the neck. In this case, transient brain ischemia caused by the anomalous course of vertebral arteries that were pinched between the $\mathrm{C} 1$ posterior arch and the pars interarticularis of C2 in cervical motion was the suspected cause of the syncope.
\end{abstract}

Keywords: Craniovertebral junction, Syncope, Vertebral artery

\section{Introduction}

Syncope can arise through several mechanisms; one wellknown cause is the vasodepressor reflex. Syncope can also be related to compression of the extracranial arteries in the neck [1]. Anomalies in the craniovertebral junction (CVJ) may be a cause of syncope, but appear to be extremely rare [2]. Mechanisms of syncope relating to CVJ anomalies remain unclear. We present here a pediatric case involving recurrent syncope and anomaly of the CVJ. The suspected mechanisms of syncope in the present case are discussed.

\section{Case presentation}

A 10-year-old Japanese boy with a 2-year history of sleep attacks or syncope was referred to our orthopedic department because his mother noted that he had been experiencing frequent falls. He had been followed up by a pediatric orthopedist for asymptomatic congenital kyphoscoliosis

\footnotetext{
* Correspondence: miyakosh@doc.med.akita-u.ac.jp

Department of Orthopedic Surgery, Akita University Graduate School of Medicine, 1-1-1 Hondo, Akita 010-8543, Japan
}

with vertebral malformations in the thoracolumbar spine. He was treated for narcolepsy by a psychiatrist, but no clear diagnostic evidence was apparent, such as abnormalities on electroencephalography. On first presentation to this department, he suddenly lost consciousness. The attack seemed more like syncope than a narcoleptic episode. The mother said he experienced such attacks three to five times a day, with each episode lasting from 30 seconds to a few minutes. After each attack, he usually fell asleep. He showed neither motor weakness nor sensory loss in his upper or lower extremities, and no bladder dysfunction was evident, but generalized hyperreflexia was identified. Electrocardiography showed normal results, and we did not observe any bradycardia at the time of syncope. Breathing likewise remained normal during syncope.

Plain lateral radiography of his CVI showed abnormal alignment with a clivo-axial angle (the angle formed by lines drawn along the clivus and the posterior aspect of the odontoid process) of $112^{\circ}$ (normal, 150 to $180^{\circ}$; Figure 1A) [3]. Lateral radiographies in flexion and extension positions 


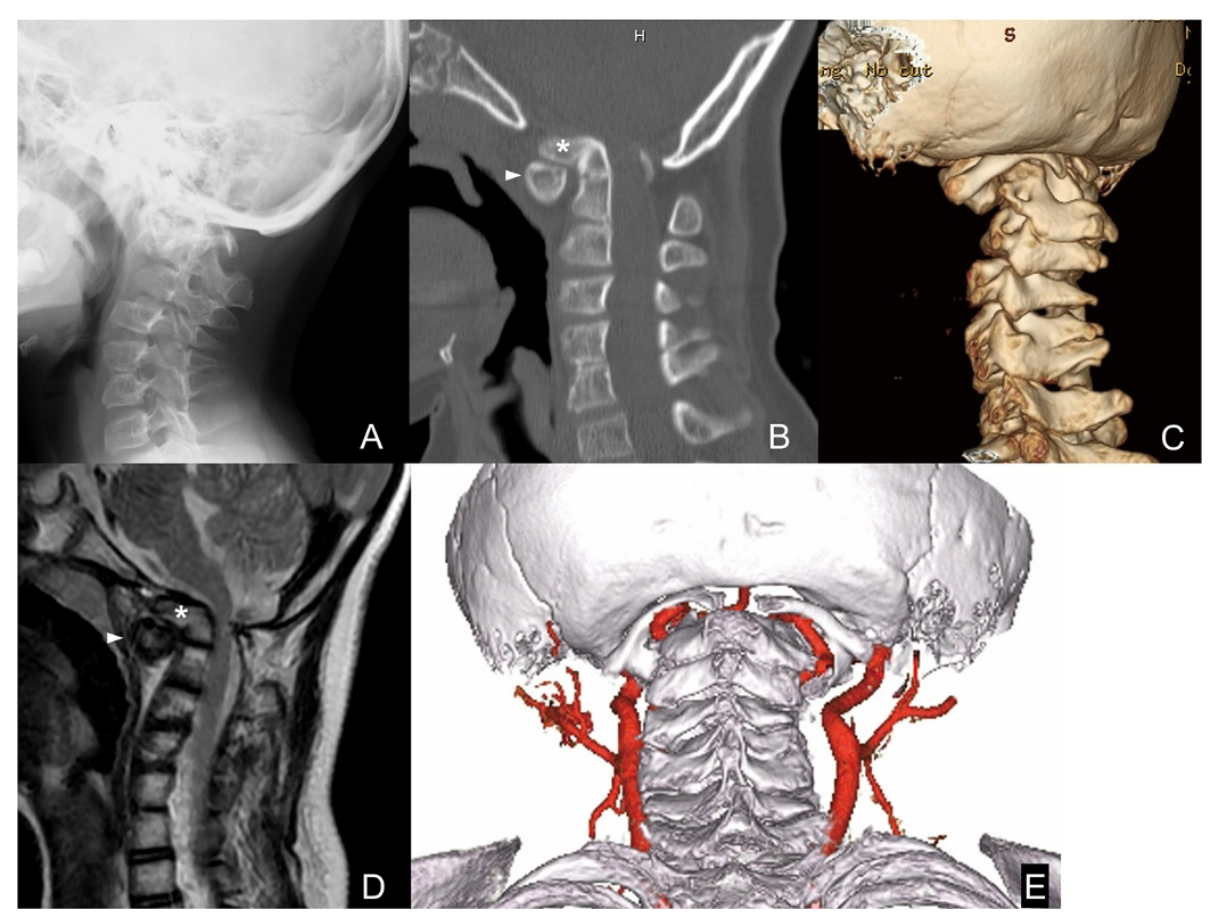

Figure 1 Preoperative imaging of the craniovertebral junction. (A) Lateral radiography shows malalignment of the craniovertebral junction. (B) Midsagittal reconstruction from computed tomography shows an anteriorly tilted odontoid process of C2 and migration of a hypoplastic C1 posterior arch into the foramen magnum. (C) Posterolateral view of three-dimensional computed tomography shows migration of the C1 posterior arch into the foramen magnum and rachischisis (spina bifida) of the C1 posterior arch. (D) Midsagittal T2-weighted magnetic resonance imaging shows compression of the spinal cord by the basilar invagination and an anteriorly shifted C1 posterior arch. (E) Posteroinferior view of three-dimensional computed tomography angiography shows anomalous courses of bilateral vertebral arteries (persistent first intersegmental artery), which were located between the C1 posterior arch and the pars interarticularis of C2. Asterisks, odontoid process; arrowheads, C1 anterior arch.

showed significant instability between $\mathrm{C} 1$ and $\mathrm{C} 2$. Computed tomography $(\mathrm{CT})$ and three-dimensional (3D)-CT of his CVJ showed an anteriorly tilted odontoid process of $\mathrm{C} 2$ and a hypoplastic $\mathrm{C} 1$ posterior arch with rachischisis (spina bifida) that was migrating into his foramen magnum (Figures $1 \mathrm{~B}$ and $1 \mathrm{C}$ ). His bilateral lateral atlantoaxial joints were dislocated anteriorly and his $\mathrm{C} 1$ anterior arch was hypertrophied. Magnetic resonance imaging showed basilar invagination and compression of his spinal cord at the C1 level (Figure 1D). Subsequent 3D-CT angiography showed abnormal courses of bilateral vertebral arteries (VAs; Figure 1E). Both VAs showed a "first persistent intersegmental artery" that entered his spinal canal at the caudal portion of the $\mathrm{C} 1$ posterior arch after emerging from the $\mathrm{C} 2$ transverse foramen, without passing through the $\mathrm{C} 1$ transverse foramen. These arteries appeared to be nearly pinched between the $\mathrm{C} 1$ posterior arch and the pars interarticularis of $\mathrm{C} 2$. The VAs at the subaxial spine were not hypoplastic. Based on these findings, we suspected that the cause of syncope was this arterial anomaly at his CVJ, and transient brain ischemia could be caused by these anomalous courses of the VAs being pinched between the $\mathrm{C} 1$ posterior arch and the pars interarticularis of $\mathrm{C} 2$ during cervical motions, especially in flexion. Posterior decompression and occiput-cervical fusion was therefore planned for decompression of the spinal cord and to prevent compression of the first persistent intersegmental arteries during motion.

$\mathrm{C} 1$ laminectomy and posterior occiput-cervical fusion (O-C2) were performed using an instrumentation system (VERTEX ${ }^{\oplus}$ MAX; Medtronic Sofamor Danek, Memphis, TN, USA). Intraoperatively, the migrated $\mathrm{C} 1$ posterior arch was repositioned after skull traction and we were able to reach the upper surface of $\mathrm{C} 1$. Decompression of his foramen magnum was therefore not required for $\mathrm{C} 1$ laminectomy. A portion of the $\mathrm{C} 1$ posterior arch rachischisis consisted of tendon-like tissue that adhered severely to the dura. During C1 laminectomy, the locations of VAs were detected using Doppler ultrasonography. C2 pedicle screws were inserted with the assistance of a navigation system (Stealth Station; ${ }^{\circledR}$ Medtronic Sofamor Danek). After C1 laminectomy and screwing, monocortical autologous bone was harvested from the right posterior iliac crest and grafted between the decorticated posterior surfaces of the occipital bone and C2.

The postoperative course was uneventful. Occiputcervical alignment appeared improved after surgery, 
with a clivo-axial angle of $130^{\circ}$ (Figure 2A). Since the surgery, he has not experienced any episodes of syncope. Cervical orthosis was applied for 6 weeks. Bone union was confirmed on $\mathrm{CT}$ at 4 months postoperatively (Figure $2 \mathrm{~B}$ ). As of the latest follow-up at 3.5 years postoperatively, he still showed no syncope, and was able to walk and run without falls.

\section{Discussion}

Congenital anomalies in the CVJ can cause numerous symptoms [4]. In an analysis of 576 surgically treated patients with anomalies in the CVJ, motor dysfunction including weakness and spasticity, sensory dysfunction, dysfunction of the vestibular cerebellum including ataxia and nystagmus, cranial nerve dysfunction including swallowing difficulty and choking on water, and dyspnea were the most common clinical symptoms [4]. All these symptoms were neurological symptoms. Syncope may also occur in patients with CVJ malformation (Table 1), but appears to be extremely rare compared with the aforementioned symptoms.

Corbett et al. [2] reported a case of syncope precipitated by sneezing in a 29 -year-old man in association with Arnold-Chiari type I malformation and basilar invagination. In that case, suboccipital craniectomy and C1-C2 laminectomies alleviated the symptoms and the authors speculated that an abnormally acute clivo-axial angle $\left(120^{\circ}\right)$, small foramen magnum, and type I Chiari malformation appeared to represent a combination of features intolerant of Valsalva-induced changes in cerebral volume, brainstem position, cerebrospinal fluid dynamics, or blood vessel relationships [2]. Pratiparnawatr et al. [5] reported the case of a 31-year-old man with basilar invagination and syringomyelia who showed cough-induced syncope. However, that patient also exhibited downbeat nystagmus, atrophy and fasciculation of the right side of
Table 1 Reported cases of craniovertebral junction malformation and syncope

\begin{tabular}{|c|c|c|c|}
\hline Author & $\begin{array}{l}\text { Age, } \\
\text { sex }\end{array}$ & $\begin{array}{l}\text { Suspected cause of } \\
\text { syncope }\end{array}$ & $\begin{array}{l}\text { Symptoms other } \\
\text { than syncope }\end{array}$ \\
\hline $\begin{array}{l}\text { Corbett } \\
\text { et al. [2] }\end{array}$ & $29 M$ & $\begin{array}{l}\text { Intolerance of Valsalva- } \\
\text { induced changes relating } \\
\text { to CVJ malalignment } \\
\text { and Chiari malformation }\end{array}$ & Dizziness \\
\hline $\begin{array}{l}\text { Pratiparnawatr } \\
\text { et al. [5] }\end{array}$ & $31 \mathrm{M}$ & Unclear & $\begin{array}{l}\text { Nystagmus, fasciculation } \\
\text { of tongue, atrophy of } \\
\text { tongue and } \\
\text { sternocleidomastoid } \\
\text { muscle, weakness of } \\
\text { extremities }\end{array}$ \\
\hline Present & $10 \mathrm{M}$ & $\begin{array}{l}\text { Bilateral persistent first } \\
\text { intersegmental arteries } \\
\text { pinched between the } \mathrm{C} 1 \\
\text { posterior arch and the } \\
\text { pars interarticularis of C2 }\end{array}$ & Frequent falls \\
\hline
\end{tabular}

CVJ, craniovertebral junction; $M$, male.

the tongue, atrophy of the right sternocleidomastoid muscle, mild weakness of the extremities, and generalized hyperreflexia. The cause of syncope was unclear in that case [5].

In the present case, although neurological factors might also have been involved, we speculated that brain ischemia caused by direct compression of bilateral anomalous VAs relating to the CVJ malformation was the major cause of syncope. Two types of anomalous course of VAs have been reported [6-9]. One is a "fenestration", showing VA duplication after emerging from the $\mathrm{C} 2$ transverse foramen; one branch enters the spinal canal between $\mathrm{C} 1$ and $\mathrm{C} 2$ and the other runs normally, passing through the $\mathrm{C} 1$ transverse foramen and entering the spinal canal on the cranial side of the posterior arch. The other is a "persistent first intersegmental artery (without persistence of the primary VA)", showing the artery entering the spinal canal at the caudal portion of the $\mathrm{C} 1$ posterior arch after emerging from the

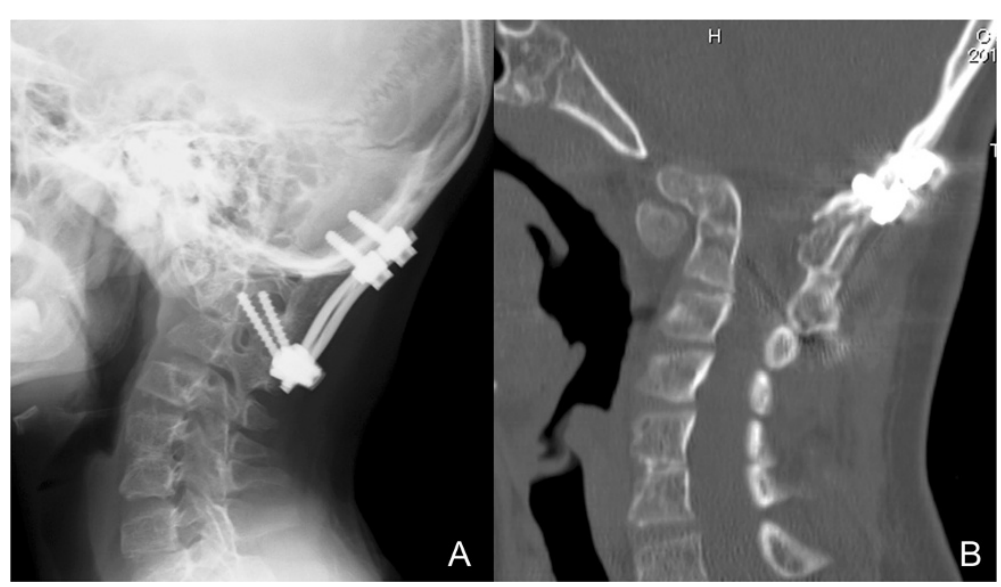

Figure 2 Postoperative imaging of the craniovertebral junction. (A) Lateral radiography shows improved alignment of the craniovertebral junction. (B) A midsagittal reconstruction of computed tomography obtained 4 months postoperatively shows complete bone union. 
$\mathrm{C} 2$ transverse foramen, without passing through the $\mathrm{C} 1$ transverse foramen. Incidences of these two VA anomalies have been reported as 0.24 to $1.0 \%$ and 0.6 to $4.7 \%$, respectively, in 300 to 1436 patients who had no symptoms from cervical spine lesions [6-8]. Usually, these VA anomalies occur unilaterally $[6,9,10]$, and bilateral cases appear to be rare. Hong et al. [6] reported that the incidence of bilateral persistent first intersegmental artery among 1013 subjects was $0.8 \%$ compared with $3.8 \%$ for unilateral cases.

Our patient showed bilateral persistent first intersegmental arteries. Bilateral persistent first intersegmental arteries usually exist on the surface of the soft dura at the $\mathrm{C} 1$ level, so spinal motion does not interfere with blood flow in the anomalous artery. However, in the present case, 3D-CT angiography clearly showed the arteries lying between the two hard structures of the $\mathrm{C} 1$ posterior arch and the pars interarticularis of $\mathrm{C} 2$. The persistent first intersegmental arteries in this patient must therefore have been pinched at this level by the $\mathrm{C} 1$ posterior arch and pars interarticularis of $\mathrm{C} 2$ during cervical motions, particularly in flexion. Subsequent changes to blood flow in the basilar artery would then have induced transient cerebral ischemia, resulting in syncope. In addition, the fact that this patient only experienced minor neurological symptoms (hyperreflexia and frequent falls, but no motor or sensory deficits) supports the hypothesis that transient brain ischemia caused by the anomalous courses of the VAs was the major cause of syncope in this case. Bow hunter's syndrome, also referred to as rotational VA occlusion syndrome [11], is a rare vascular phenomenon that can be a differential diagnosis for transient cerebral ischemia caused by VA compression. However, bow hunter's syndrome usually occurs with cervical rotation in patients with an anatomically normal skeleton and VAs, whereas syncope in the present case was not induced by cervical rotation but rather suspected flexion in a patient with skeletal anomaly and bilateral anomalous VAs. We therefore excluded the possibility of bow hunter's syndrome in the present case.

\section{Conclusions}

We have presented an extremely rare case of congenital anomaly in the CVJ resulting in recurrent syncope. Posterior decompression and occiput-cervical fusion relieved all symptoms. Symmetrical anomaly of the VAs (bilateral persistent first intersegmental arteries) pinched by the osseous structures $(\mathrm{C} 1$ posterior arch and pars interarticularis of $\mathrm{C} 2$ ) during occipital-cervical motion was the suspected cause of syncope.

\section{Consent}

Written informed consent was obtained from the patient's legal guardians for publication of this case report and the accompanying images. A copy of the written consent is available for review by the Editor-in-Chief of this journal.

\section{Abbreviations}

3D: Three-dimensional; CT: Computed tomography; CVJ: Craniovertebral junction; VA: Vertebral artery.

\section{Competing interests}

The authors declare that they have no competing interests.

\section{Authors' contributions}

NM performed the surgery and prepared the manuscript. MH, YK, and YS assisted in drafting the manuscript and reviewed the article. All authors read and approved the final manuscript.

\section{Acknowledgements}

We wish to thank Dr Akiko Misawa for help with data collection.

Received: 28 May 2014 Accepted: 20 August 2014

Published: 8 October 2014

\section{References}

1. Janczak D, Skora J, Rucinski A, Szuba A: Recurrent syncope caused by compression of internal carotid artery by an anomalous hyoid bone. Vasa 2012, 41(3):221-224.

2. Corbett JJ, Butler AB, Kaufman B: 'Sneeze syncope", basilar invagination and Arnold-Chiari type I malformation. J Neurol Neurosurg Psychiatry 1976, 39(4):381-384

3. Smoker WR: Craniovertebral junction: normal anatomy, craniometry, and congenital anomalies. Radiographics 1994, 14(2):255-277.

4. Li L, Yu X, Wang P, Chen L: Analysis of the treatment of 576 patients with congenital craniovertebral junction malformations. J Clin Neurosci 2012, 19(1):49-56.

5. Pratiparnawatr $P$, Tiamkao S, Tanapaisal C, Kanpittaya J, Jitpimolmard S: Downbeating nystagmus and postural hypotension due to basilar invagination. J Med Assoc Thai 2000, 83(12):1530-1534.

6. Hong JT, Lee SW, Son BC, Sung JH, Yang SH, Kim IS, Park CK: Analysis of anatomical variations of bone and vascular structures around the posterior atlantal arch using three-dimensional computed tomography angiography. J Neurosurg Spine 2008, 8(3):230-236.

7. Sato K, Watanabe T, Yoshimoto T, Kameyama M: Magnetic resonance imaging of C2 segmental type of vertebral artery. Surg Neurol 1994, 41(1):45-51

8. Tokuda K, Miyasaka K, Abe H, Abe S, Takei H, Sugimoto S, Tsuru M: Anomalous atlantoaxial portions of vertebral and posterior inferior cerebellar arteries. Neuroradiology 1985, 27(5):410-413.

9. Yamazaki M, Okawa A, Hashimoto M, Aiba A, Someya Y, Koda M: Abnormal course of the vertebral artery at the craniovertebral junction in patients with Down syndrome visualized by three-dimensional CT angiography. Neuroradiology 2008, 50(6):485-490

10. Yamazaki M, Okawa A, Furuya T, Sakuma T, Takahashi H, Kato K, Fuijyoshi T, Mannoji C, Takahashi K, Koda M: Anomalous vertebral arteries in the extra- and intraosseous regions of the craniovertebral junction visualized by 3-dimensional computed tomographic angiography: analysis of 100 consecutive surgical cases and review of the literature. Spine (Phila Pa 1976) 2012, 37(22):E1389-E1397.

11. Cornelius JF, George B, N'dri Oka D, Spiriev T, Steiger HJ, Hänggi D: Bow-hunter's syndrome caused by dynamic vertebral artery stenosis at the cranio-cervical junction - a management algorithm based on a systematic review and a clinical series. Neurosurg Rev 2012, 35(1):127-135.

doi:10.1186/1752-1947-8-330

Cite this article as: Miyakoshi et al:: Syncope caused by congenital anomaly at the craniovertebral junction: a case report. Journal of Medical Case Reports 2014 8:330. 